\title{
QUANTIFICATION OF INFORMATION IN THE CLOSED STRUCTURE OF A TECHNICAL SYSTEM
}

\author{
Dulesov Aleksandr Sergeevich \\ Khrustalev Vitaly Igorevich \\ Katanov Khakas State University \\ Abakan, Russian Federation \\ Dulesov@khsu.ru
}

\author{
Dulesova Natalia Valeriyvna \\ Khakas Technical Institute of Siberian Federal University \\ Abakan, Russian Federation \\ Dulesovanv@mail.ru
}

\begin{abstract}
The article shows a technique to quantify information within the structure of a technical system. The structure indicators are accepted as probability states $s$ of the system elements that are differentiated into two opposite states according to a qualitative attribute. The author gives mathematical expressions to present calculation aimed at quantification of informational entropy. The technique is based on decomposition of the initial structure into two schemes (seriesparallel and parallel-series) as regard to a singular element. The information is quantified for each scheme according to the presented formulae. The final result was gained by adding quantity of information of each scheme with due account for the information of a singular element. The obtained results were compared to similar values calculated by the method of full enumeration of system element states. Thus, there were defined errors of the calculations. The offered method allows to select a system with a higher efficiency level or structural reliability due to the comparison of entropy values of opposite states.
\end{abstract}

Keywords-information measure; informational entropy; technical system structure

Introduction. Technological process control systems require high reliability at their functioning. To provide this, analytical calculation of block or logical diagrams has been used in design and operation of the systems. These methods allow to define probabilities of two opposite system states: operable and non-operable states. This case does not exclude the analysis of systems from the position of existence of information uncertainty as the nature of occurrence of the events is probabilistic. The quantitative measure of uncertainty allows to assess the efficiency of a system structure to define its reliability. This measure of uncertainty is the quantity of the informational entropy that can be calculated by the technique presented in this paper. The technique is based on equivalenting of series and parallel structures [1] equivalent with due account for the structure decomposition as regard to a singular element. Further, there offered a procedure of entropy quantification for the opposite (non-crossing) probabilistic states of system elements.
Quantification of entropy by the structure decomposition. Based on the statistics, preliminary calculation involves calculation of probabilities $\mathrm{p}_{\mathrm{i}}$ and $\mathrm{q}_{\mathrm{i}}=1-\mathrm{p}_{\mathrm{i}}$ of finding i element of the system in the two opposite states. According to the analysis of $\mathrm{p}_{\mathrm{i}}$ and $\mathrm{q}_{\mathrm{i}}$ reliability they correspond to the probability of operable and non-operable states of i element. Their calculation can involve statistics: time duration of one or another element state; frequency of one or another event occurrence, etc.

It is possible to quantify entropy of one $i$ element taking into account its entropy division into qualitative components (operable and non-operable states) and using K.Shannon's equation:

$$
H_{i}=-\left(p_{i} \log _{2} p_{i}+q_{i} \log _{2} q_{i}\right) .
$$

The equation (1) is correct under condition that $p_{i}+q_{i}=1$. Value $H_{i}$ is measured by bit, and the logarithm base that equals 2 shows the two opposite states.

As system elements are in the opposite states, due to (1) one can get total entropy:

$$
H_{\Sigma}=-\sum_{i=1}^{N}\left[H\left(p_{i}\right)+H\left(q_{i}\right)\right]=-\sum_{i=1}^{N}\left(p_{i} \log _{2} p_{i}+q_{i} \log _{2} q_{i}\right),
$$

(2) where $N$ is a number of elements in the system structure, $H\left(p_{i}\right)$ and $H\left(q_{i}\right)$ correspond to entropies of operable and nonoperable states of $i$ element. When all $p_{i}=q_{i}=0.5$, due to (2) one gets maximum entropy $H_{\max }=H_{\Sigma}=N$. Equation (2) is necessary to monitor the correctness of the fulfilled calculations.

A number of $\mathrm{N}$ elements which states are considered to be independent as well as a type of the scheme of the elements connection are important for calculation of qualitative components of total entropy. In cases when the scheme has closed appearance, it should be transformed to obtain the form of schemes of elements in parallel and series connection. The newly obtained schemes will allow to apply the offered technique based on equivalent transformations [5]. When equivalenting the schemes it is necessary to meet a requirement: the quantity of information in the initial structure has to be equal to the quantity of information in the transformed schemes. To follow this requirement it is 
necessary to reduce the entropy quantity of each element of the initial structure by the number of its repetitions in the newly transformed schemes.

Mathematical model of entropy quantification. The structure of two or three elements connected in parallel or in series is considered a simplest one. The model development is based on the research results presented in works [2,3] and $[4,5]$, where the entropy value of superposition and intersection of two interdependent events is determined from geometric surface formed, on the one hand, by the event probability, on the other hand, by the proper information inherent to the event.

Probabilities $p_{i}+q_{i}=1$ are common to each element $i$ of the structure. The hypotheses of the opposition and independence of the events inherent to an element allows quantifying the entropy using equation (1). Two elements can simultaneously be in a mergeable state, while their entropy qualities $H(p)$ for two independent events, e.g. with probabilities $p_{1}$ and $p_{2}$, being as following:

- for joint entropy (with account of combined probability $\left.p_{1} p_{2}\right)$,

$H\left(p_{1} p_{2}\right)=-p_{1} p_{2} \log _{2} p_{1}-p_{1} p_{2} \log _{2} p_{2}=p_{2} H\left(p_{1}\right)+p_{1} H\left(p_{2}\right)$,

where $H\left(p_{1}\right)=-p_{1} \log _{2} p_{1}, H\left(p_{2}\right)=-p_{2} \log _{2} p_{2}$;

- for conventional entropy (with account of conventional probabilities $p_{1} / p_{2}$ and $\left.p_{2} / p_{1}\right)$,

$$
\begin{aligned}
& H\left(p_{1} / p_{2}\right)=H\left(p_{1}\right)-p_{1} H\left(p_{2}\right) ; \\
& H\left(p_{2} / p_{1}\right)=H\left(p_{2}\right)-p_{2} H\left(p_{1}\right) .
\end{aligned}
$$

$H\left(p_{1} / p_{2}\right)+H\left(p_{2} / p_{1}\right)=H\left(p_{1}\right)+H\left(p_{2}\right)-H\left(p_{1} \cdot p_{2}\right)=p_{1} \log _{2} p_{1}+$ $+p_{2} \log _{2} p_{2}-p_{2} H\left(p_{1}\right)-p_{1} H\left(p_{2}\right)$.

Equations (3)-(6) do not allow entropy division into qualitative constituents. To divide entropy it is necessary to look into the system reliability calculation that needs a search method for all independent conditions of the system elements. The complete search of independent conditions for two elements $(n=2)$ allows to get equation of $2^{n}$ cross events:

$$
p_{1} p_{2}+p_{1} q_{2}+p_{2} q_{1}+q_{1} q_{2}=1 \text {. }
$$

Taking into account the process of getting equation (3) and applying it in a similar way for the three other elements in formula (7), it is possible to develop the function of total entropy quantification for two independent elements:

$$
\begin{aligned}
& H_{\Sigma 2}=-\left(p_{1} p_{2} \log _{2} p_{2}+p_{1} p_{2} \log _{2} p_{1}+p_{1} q_{2} \log _{2} q_{2}+p_{1} q_{2} \log _{2} p_{1}+\right. \\
& \left.+p_{2} q_{1} \log _{2} q_{1}+p_{2} q_{1} \log _{2} p_{2}+q_{1} q_{2} \log _{2} q_{2}+q_{1} q_{2} \log _{2} q_{1}\right) .
\end{aligned}
$$

(8)

Equation (8) is written over as following:

$$
\begin{aligned}
& H_{\Sigma 2}=p_{1} H\left(p_{2}\right)+p_{2} H\left(p_{1}\right)+p_{1} H\left(q_{2}\right)+q_{2} H\left(p_{1}\right)+ \\
& +p_{2} H\left(q_{1}\right)+q_{1} H\left(p_{2}\right)+q_{1} H\left(q_{2}\right)+q_{2} H\left(q_{1}\right)= \\
& =H\left(p_{1}\right)+H\left(q_{1}\right)+H\left(p_{2}\right)+H\left(q_{2}\right) .
\end{aligned}
$$

Entropy can be defined from (9):

$$
\begin{aligned}
& \text { - joint, } H_{2}\left(p_{1} p_{2}\right)=p_{1} H\left(p_{2}\right)+p_{2} H\left(p_{1}\right) \text {; } \\
& \text { - conventional, } H_{2}(q / p)=H\left(q_{1}\right)+H\left(q_{2}\right)+q_{1} H\left(p_{2}\right)+q_{2} H\left(p_{1}\right) \text {. }
\end{aligned}
$$

Formula (11) can be presented in a different way to eliminate $H\left(p_{i}\right)$ from it and to follow the condition
$H_{i}=H\left(p_{i}\right)+H\left(q_{i}\right):$

$H_{2}(q / p)=H\left(q_{1}\right)+H\left(q_{2}\right)+q_{1}\left[H_{2}-H\left(q_{2}\right)\right]+q_{2}\left[H_{1}-H\left(q_{1}\right)\right]$.

Further, there analyzed three elements that can be in a mergeable state. The complete search for three elements $(n=3)$ allows to get equation of $2^{n}$ cross events:

$p_{1} p_{2} p_{3}+p_{1} q_{2} p_{3}+p_{1} q_{2} q_{3}+p_{1} p_{2} q_{3}+q_{1} q_{2} q_{3}+q_{1} p_{2} q_{3}+p_{1} q_{2} q_{3}+q_{1} q_{2} p_{3}=1$. (13)

By analogy with formula (9) it is possible to develop the function of total entropy quantification for three independent elements:

$$
\begin{aligned}
& H_{\Sigma 3}=p_{1} p_{2} H\left(p_{3}\right)+p_{1} p_{3} H\left(p_{2}\right)+p_{2} p_{3} H\left(p_{1}\right)+\ldots \\
& \ldots+q_{1} q_{2} H\left(p_{3}\right)+q_{1} p_{3} H\left(q_{2}\right)+q_{2} p_{3} H\left(q_{1}\right)= \\
& =H\left(p_{1}\right)+H\left(q_{1}\right)+\ldots+H\left(p_{3}\right)+H\left(q_{3}\right) .
\end{aligned}
$$

Providing for $p_{i}+q_{i}=1$, after transformations, one can put equation (14) in the following way:

$$
\begin{aligned}
& H_{\Sigma 3}=p_{1} p_{2} H\left(p_{3}\right)+p_{1} p_{3} H\left(p_{2}\right)+p_{2} p_{3} H\left(p_{1}\right)+ \\
& +H\left(q_{1}\right)+\left(q_{2}+q_{3}-q_{2} q_{3}\right)\left[H_{1}-H\left(q_{1}\right)\right]+ \\
& +H\left(q_{2}\right)+\left(q_{1}+q_{3}-q_{1} q_{3}\right)\left[H_{2}-H\left(q_{2}\right)\right]+ \\
& +H\left(q_{3}\right)+\left(q_{1}+q_{2}-q_{1} q_{2}\right)\left[H_{3}-H\left(q_{3}\right)\right]= \\
& =H\left(p_{1}\right)+H\left(q_{1}\right)+\ldots+H\left(p_{3}\right)+H\left(q_{3}\right)=n, n=3 .
\end{aligned}
$$

Formula (15) includes joint and conventional entropy:

$$
\begin{aligned}
& H_{\Sigma 3}=H_{3}\left(p_{1} p_{2} p_{3}\right)+H_{3}(q / p)= \\
& =H\left(p_{1}\right)+H\left(q_{1}\right)+\ldots+H\left(p_{3}\right)+H\left(q_{3}\right)=n .
\end{aligned}
$$

Equation (16) shows:

- joint entropy or entropy of operative condition,

$$
H_{3}\left(p_{1} p_{2} p_{3}\right)=H_{3}(P)=p_{1} p_{2} H\left(p_{3}\right)+p_{1} p_{3} H\left(p_{2}\right)+p_{2} p_{3} H\left(p_{1}\right) ;
$$

- conventional entropy or entropy of inoperative condition,

$$
\begin{aligned}
& H_{3}(q / p)=H_{3}(Q)=H\left(q_{1}\right)+\left(q_{2}+q_{3}-q_{2} q_{3}\right)\left[H_{1}-H\left(q_{1}\right)\right]+ \\
& +H\left(q_{2}\right)+\left(q_{1}+q_{3}-q_{1} q_{3}\right)\left[H_{2}-H\left(q_{2}\right)\right]+ \\
& +H\left(q_{3}\right)+\left(q_{1}+q_{2}-q_{1} q_{2}\right)\left[H_{3}-H\left(q_{3}\right)\right] .
\end{aligned}
$$

If $q_{3}=0$ and $H\left(p_{3}\right)+H\left(q_{3}\right)=0$ are inserted into equation (18), one can pass to the entropy of two elements, that is to formula (12).

The developed mathematical model makes it possible to present a calculation procedure of the entropy of a closed structure system. The calculation procedure is connected with the development of parallel and series schemes of the structure as regard to its singular element, the probability of the latter being taken to be equal to 1 as well as to 0 .

The procedure of entropy quantification.

1. To quantify entropy of each $N$ element according to (1):

- for operable state of $i$ element $-H\left(p_{i}\right)=-p_{i} \log _{2} p_{i}$;

- for non-operable state of $i$ element- $H\left(q_{i}\right)=-q_{i} \log _{2} q_{i}(20)$ 
2. To transform the initial structure (Illustration 1) into the appearance of the two series-parallel and parallel-series schemes.

3. To quantify entropy of each $k$ element of the constructed schemes:

- for operable state $\quad H\left(p_{k}\right)=\frac{1}{l} H\left(p_{i}\right) ;$

- for non-operable state $\quad H\left(q_{k}\right)=\frac{1}{l} H\left(q_{i}\right)$;

where $l$ is a number of repetitions of $i$ element in the newly transformed schemes, $k$ is the ordinal number of the element in the scheme.

4. To quantify entropy:

A. For a series-parallel scheme of paths:

- probability of the operable state of the elements of $j$ path

$$
P_{j}=\prod_{k=1}^{n_{j}} p_{k}
$$

where $p_{k}$ is probability of the operable state of $k$ element,

$j$ path, $n_{j}$ is a number of elements in the path;

- probability of the non-operable state of $j$ path

$$
-Q_{j}=1-P_{j}
$$

- entropy of the operable state of $j$ path -

$$
H\left(P_{j}\right)=\sum_{i=1}^{n_{j}}\left[\left(\prod_{\substack{k=1 \\ k \neq i}}^{n_{j}} p_{k}\right) H\left(p_{i}\right)\right] ;
$$

- entropy of the non-operable state of $j$ path

$$
H\left(Q_{j}\right)=\sum_{k=1}^{n_{j}}\left[H\left(p_{k}\right)+H\left(q_{k}\right)\right]-H\left(P_{j}\right) ;
$$

- entropy of the operable state of the series-parallel scheme-

$$
H\left(P_{I}\right)=\sum_{j=1}^{m}\left[H\left(P_{j}\right)+\left(1-\prod_{\substack{k=1 \\ k \neq j}}^{m} Q_{j}\right) H\left(Q_{j}\right)\right],
$$

where $m$ is a number of paths in the scheme;

- entropy of the non-operable state of the series-parallel scheme $-H\left(Q_{I}\right)=\sum_{k=1}^{N_{I}}\left[H\left(p_{k}\right)+H\left(q_{k}\right)\right]-H\left(P_{I}\right)$,

where $N_{I}$ is a number of elements in the series-parallel scheme.

B. For a series-parallel scheme of cutsets:

- probability of the non-operable state of $j$ cutset -

$$
Q_{j}=\prod_{k=1}^{n} q_{k}
$$

where $q_{k}$ is probability of the non-operable state of $k$ element, $j$ cutset, $n_{j}$ is a number of elements in the cutset;

- probability of the operable state of $j$ cutset -

$$
P_{j}=1-Q_{j}
$$

- entropy of the non-operable state of elements of $j$ cutset

$$
H\left(Q_{j}\right)=\sum_{i=1}^{n_{j}}\left[\left(\prod_{\substack{k=1 \\ k \neq i}}^{n_{j}} q_{k}\right) H\left(q_{i}\right)\right] ;
$$

- entropy of the operable state of elements of $j$ cutset -

$$
H\left(P_{j}\right)=\sum_{k=1}^{n_{j}}\left[H\left(p_{k}\right)+H\left(q_{k}\right)\right]-H\left(Q_{j}\right) ;
$$

- entropy of the non-operable state of the parallel-series scheme $-H\left(Q_{I I}\right)=\sum_{j=1}^{m}\left[H\left(Q_{j}\right)+\left(1-\prod_{k=1}^{m} P_{j}\right) H\left(P_{j}\right)\right]$,

$$
k \neq j
$$

where $m$ is a number of cutsets in the scheme;

- entropy of the operable state of the parallel-series scheme -

$$
H\left(P_{I I}\right)=\sum_{k=1}^{N_{I I}}\left[H\left(p_{k}\right)+H\left(q_{k}\right)\right]-H\left(Q_{I I}\right) ;
$$

where $N_{I I}$ is a number of elements in the parallel-series scheme.

5. To quantify the system entropy:

$$
\begin{aligned}
& \text { - of the operable state } \\
& H(P)=H\left(P_{I}\right)+H\left(P_{I I}\right)+H\left(p_{u}\right)+H\left(q_{u}\right) \text {; } \\
& \text { - of the non-operable state }
\end{aligned}
$$

$H(Q)=H\left(Q_{I}\right)+H\left(Q_{I I}\right)+H\left(p_{u}\right)+H\left(q_{u}\right)$,

where $u$ symbol means the number of a singular element (Illustration 1), with regard to which the initial structure has been decomposed. Its entropy is quantified according to equations (5) and (6), where $l$ is a number of newly transformed series and parallel schemes.

6. Total entropy: $H_{\Sigma}=H(P)+H(Q)$

Illustration 1. Decomposition of the bridge structure (Fig.1) as regard to a singular element.

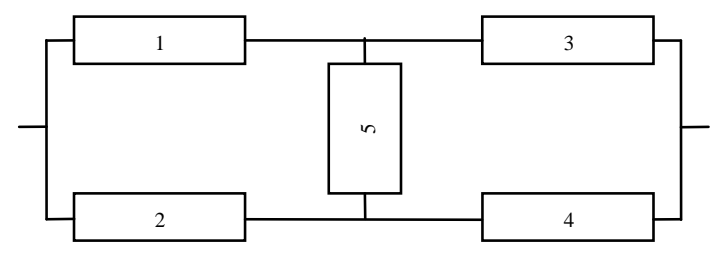

Fig. 1. Bridge structure (scheme)

Fig. 1 shows element Number 5 a singular element which is considered absolutely unreliable for the composition of series-parallel scheme $\left(p_{5}=0\right)$, and absolutely reliable for a 
parallel-series scheme $\left(p_{5}=1\right)$. The transformed schemes with regard to this element are shown in Figures 2 and 3.

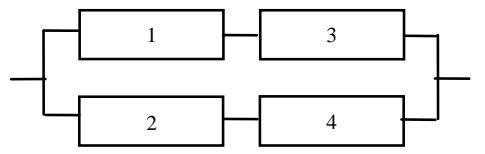

Fig. 2. Series-parallel scheme of paths

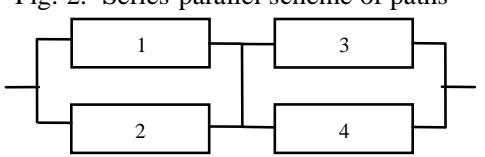

Fig. 3. Parallel-series scheme of cutsets

The entropy quantification is performed according to the presented calculation. The final outcomes obtained due to formulae (19) and (20) were compare to the results in [2]. Therefore, the errors in the calculations do not accede $13,5 \%$.

Conclusion. The offered technique to quantify entropy can be used for the analysis of the opposed probabilistic states of a technical system. The analysis involves a closed structure which is decomposed into the schemes of elements of seriesparallel and parallel-series connection after defining of a singular element in it. The quantity of entropy obtained due to this technique and by means of comparative assessments of the considered versions of system structures allows to select a more reliable and efficient structure.

\section{REFERENCES}

[1] Dulesov A.S., Kondrat N.N., "Ekvivalentirovanie kolichestva informatsionnoy entropii v strukture tekhnicheskoy sistemy," Zhurnal Fundamental'nye issledovaniya., Moscow, vol. 6, (chast' 1), pp. 14-19, 2015 .

[2] Dulesov A.S., Kondrat N.N. "Opredelenie kolichestva informatsionnoy entropii V strukture tekhnicheskoy sistemy metodom perebora sostoyaniy," Fundamental'nye issledovaniya., Moscow, vol. 7, (chast' 4), pp. 745-748, 2015.

[3] Dulesov A. S., Kabaeva E. V. Logarifmicheskaya mera informatsii sostoyaniya tekhnicheskogo ob"ekta // «Sovremennye problemy nauki i obrazovaniya». №1 (Elektronnyy zhurnal); URL: www.scienceeducation.ru/107-8210, 2013.

[4] Dulesov A.S., Kondrat N.N. Mera neopredelennosti informatsii i ee svoystva primenitel'no $\mathrm{k}$ otsenke sluchaynogo povedeniya tekhnicheskogo ob"ekta // Zhurnal «Nauchnoe obozrenie». №7. pp.258-264., 2014.

[5] Dulesov A.S., Kondrat N.N. Kolichestvo informatsii pri nalozhenii i peresechenii elementarnykh sobytiy // Zhurnal «Nauchnoe obozrenie». №12., pp.146-150, 2014.

[6] Dulesov A.S., Kondrat N.N. Opredelenie kolichestva informatsionnoy entropii $\mathrm{V}$ strukture tekhnicheskoy sistemy metodom perebora sostoyaniy // Zhurnal «Fundamental'nye issledovaniya». № 7, (chast' 4). - pp. 745-748., 2015 